\title{
Lingual Thyroid Causing Dysphagia: A Case Report and Review of Literature
}

\section{Ralli M*, Singh G, Parmar P, Gilotra M, Kalyan S and Brar K}

Pt Bhagwat Dayal Sharma Post Graduate Institute of Medical Sciences Rhotak, India

"Corresponding author: Megha Ralli, Pt Bhagwat Dayal Sharma Post Graduate Institute of Medical Sciences Rhotak, 01125257458, India, Tel: 917206191047; E-mail: drmegharalli@gmail.com

Received date: June 02, 2016; Accepted date: July 20, 2016; Published date: July 25, 2016

Copyright: @ 2016 Ralli M, et al. This is an open-access article distributed under the terms of the Creative Commons Attribution License, which permits unrestricted use, distribution, and reproduction in any medium, provided the original author and source are credited.

Abstract
Introduction: Lingual thyroid is the presence of thyroid tissue in the midline anywhere between the circumvallate
papillae of tongue and the epiglottis. It occurs due to embryonic failure of normal thyroid tissue to descend from
base of tongue to neck.
Case report: A 16 year old female presented with dysphagia and a mass was seen at base of tongue. Ultrasound
showed absence of normal thyroid gland in neck. Fine needle aspiration cytology of mass showed thyroid follicles
with colloidal changes, thus, confirming the diagnosis of ectopic thyroid (lingual).
Conclusion: Lingual thyroid is rare developmental anomaly and must be kept as differential in tongue masses
cases. Surgical excision is treatment of choice.

Keywords: Lingual thyroid; Dysphagia; FNAC; Surgery

\section{Introduction}

The thyroid gland is one of the largest endocrine glands in the body and lies approximately at the same level as the cricoid cartilage [1,2]. Lingual thyroid is defined as the presence of thyroid tissue in the midline anywhere between the circumvallate papillae of tongue and the epiglottis. The condition arises from the embryonic failure of normal thyroid tissue to descend from the foramen cecum area of the tongue base through the lower neck, and presents as a lobular midline mass in the mucosal surface of the tongue base [3]. Lingual thyroid is a rare anomaly with an incidence of 1 in 3000 of the thyroid cases seen and with overall prevalence of 1 in 100,000. Sites of local thyroid deposition include cervical lymph nodes, submandibular glands and trachea. Of all ectopic thyroids $90 \%$ are found to be lingual thyroids [4]. Very rarely, two ectopic foci may be present simultaneously $[5,6]$. Approximately two thirds of the patients with lingual thyroid lack thyroid tissue in neck. Lingual thyroid is four times more common in females than in males.4 Diagnosis of lingual thyroid includes local examination of the tongue base associated with the absence of normally located gland, and imaging examinations. Imaging studies include neck ultrasound, neck CT-scan, neck-IRM and scintigraphy using Tc 99m, I-131, I-123 [7]. Fine needle aspiration cytology (FNAC) is required for confirmation of diagnosis and helps to distinguish benign from malignant lesion. We report a case of lingual thyroid presenting with dysphagia, which was diagnosed on FNAC.

\section{Case Report}

A 16 year old female presented in surgery OPD with complaint of progressive dysphagia since one week. There was no significant past medical history. Physical examination revealed a small midline mass with intact mucosa covering it at the base of the tongue (Figure 1).

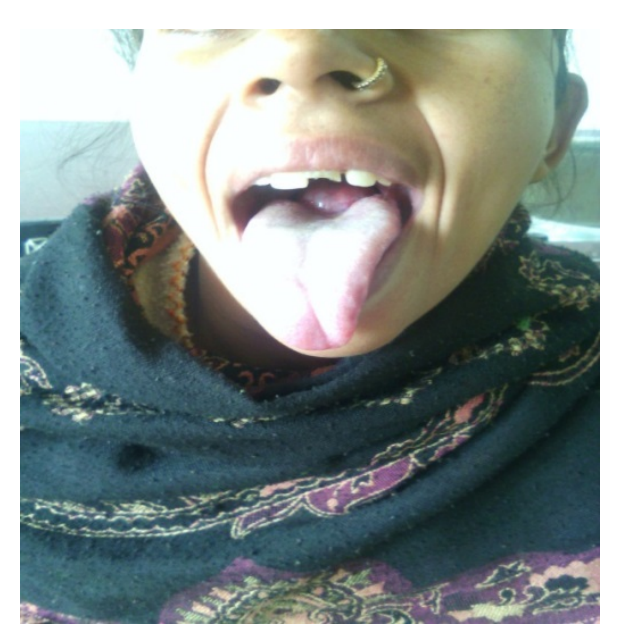

Figure 1: A small nodular midline mass with intact mucosa covering it at the base of the tongue.

According to the patient, this mass was increasing in size since one week. There was no palpable thyroid in neck. Ultrasound neck revealed absence of thyroid in its normal anatomic location. Thyroid function tests demonstrated normal T3 and T4 levels with increased TSH levels. Fine needle aspiration from base of tongue mass revealed follicular epithelial cells arranged in groups, clusters and forming microfollicles in background of colloid and RBCs (Figure 2). 


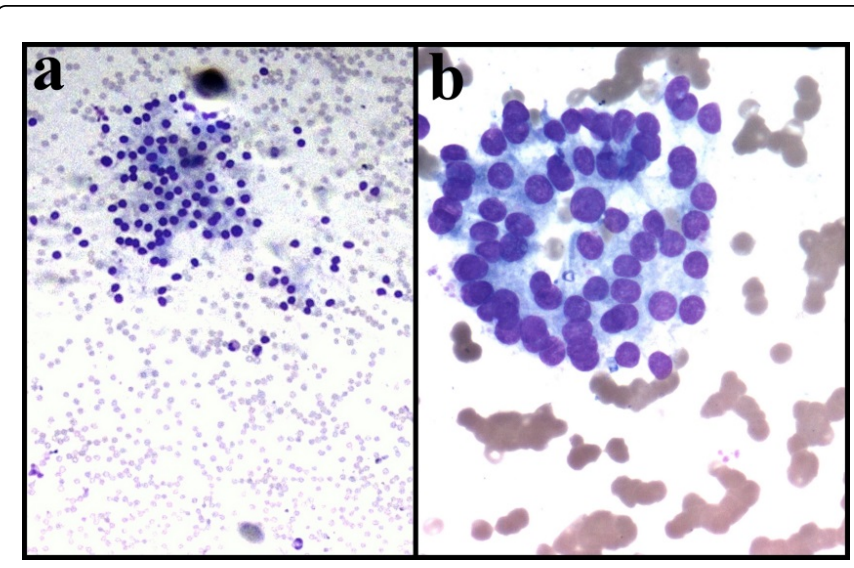

Figure 2: Fine needle aspiration from mass showing follicular epithelial cells forming microfollicles in background of colloid and RBCs (Leishman, 40X, 400X).

The final diagnosis of lingual thyroid was made. Patient was given thyroid hormone therapy for reduction in the size of gland. Patient is on regular follow up since then.

\section{Discussion}

Hickmann recorded the first case of lingual thyroid in 1869. Montgomery stated that for a case to be called as lingual thyroid, thyroid follicles should be seen histopathologically in tissues sampled from the lesion [8]. Few theories state that, early in embryogenesis thyroid gland appears as proliferation of endodermal tissue in the floor of the pharynx between tuberculum impar and hypobranchial eminence (foramen cecum) [9]. Normally thyroid gland descends along a path from foramen cecum in the tongue, passes the hyoid bone, to the final position in front and lateral to the second, third, and fourth tracheal rings by 7 weeks of gestation. During this descent thyroid tissue retains its connection with foramen cecum and is known as thyroglossal duct. Once the thyroid tissue reaches its midline position, the thyroglossal duct degenerates [10]. Persistence of this duct even after birth results in formation of thyroglossal cyst. The descent may arrest anywhere along this path and this condition may remain unnoticed until puberty. Any functioning thyroid tissue found outside of the normal thyroid location is termed ectopic thyroid tissue.

Ectopic tissue has also been noted in the mediastinum, heart, esophagus, and diaphragm. Lingual thyroid is the result of failure of descent of the thyroid from the foramen cecum of the tongue [8]. Some authors state that maternal antithyroid immunoglobulins may impair gland descent during early fetal life [3].

About 33-62\% of all patients with ectopic thyroid show hypothyroidism with increased levels of TSH, as was seen in our case [11]. Patients with lingual thyroid either present in infancy or childhood with features of failure to thrive or delayed development or may present in adult life with symptoms of dysphagia or dysphonia. Before or during puberty there is increased demand of thyroxine which leads to increased functioning of ectopic thyroid. This results in increase in size of thyroid tissue, hence patients present with dysphagia or dysphonia. Similar response can also be seen during other metabolic stress conditions like pregnancy, infections, trauma, menopause etc. [8].
Diagnosis is based on absence of normal thyroid gland in neck by ultrasound and technetium scan. Fine needle aspiration cytology (FNAC) confirms the diagnosis of ectopic thyroid. It is the only modality to differentiate between benign and malignant lesion [3]. Most of the cases are benign, however few malignant cases have also been reported [12]. Thyroid scan can also reveal whether there are other sites of thyroid tissue. In approximately $75 \%$ of patients the ectopic tissue is the only functioning thyroid tissue in the body [13]. Differential diagnosis in such cases includes lymphangioma, minor salivary gland tumors, midline branchial cysts, thyroglossal duct cysts, epidermal and sebaceous cysts, angioma, adenoma, fibroma and lipoma [11].

Regular follow- up is recommended for cases completely asymptomatic and euthyroid in order to detect mass complications [7]. Substitutive therapy with thyroid hormone may be successful in reducing the size of the mass in patients with mild clinical symptoms, as was seen in our case. Since rare malignant transformations are reported, some authors re surgical removal as the treatment option $[14,15]$. In patients not fit for surgery, radioiodine ablative therapy can also be given. This treatment is however avoided in young patients to prevent radiation damage in gonads [7]. Computed tomography scans are necessary for planning surgical intervention and the approach [11]. Although various types of surgeries have been described, the transoral approach provides good exposure and is less traumatic for the patient and has better postoperative recovery [3]. In patients lacking thyroid tissue in the neck, the lingual thyroid may be excised and autotransplanted to the muscles of the neck [16]. As the lingual thyroid is the only functioning thyroid tissue found in $70 \%$ of these patients, levothyroxine therapy should be initiated after surgical excision. 8 Follow-up is recommended to monitor possible recurrence or complications.

\section{Conclusion}

Lingual thyroid is rare developmental entity which may present as dysphagia or dysphonia. It should be included in differential diagnosis of tongue masses especially in children and adolescence. Physical examination, thyroid function tests and radionuclide scanning are essential for making diagnosis. FNAC is important in to exclude rare possibility of malignancy. Transoral approach of surgical excision followed by levothyroxine therapy is best treatment option available.

\section{References}

1. Stoppa-Vaucher S, Lapointe A, Turpin S, Rydlewski C, Vassart G, et al. (2010) Ectopic thyroid gland causing dysphonia: imaging and molecular studies. J Clin Endocrinol Metab 95: 4509-4510.

2. Fogarty D (1990) Lingual thyroid and difficult intubation. Anaesthesia 45: 251.

3. Williams JD, Sclafani AP, Slupchinskij O, Douge C (1996) Evaluation and management of the lingual thyroid gland. Ann Otol Rhinol Laryngol 105: 312-316.

4. Anand CSS, Sood V, Kumar CPG, Suryanarayna CKM, Kotwal NC (2006) Lingual Thyroid. MJAFI 62: 184-185.

5. Chawla M, Kumar R, Malhotra A (2007) Dual ectopic thyroid: case series and review of the literature. Clinical Nuclear Medicine 32: 1-5.

6. Rao PN, Pandit N, Kumar R, Upadhya IV, Vidya Sagar MS (2005) Ectopic functioning thyroid tissue in the thyroglossal duct detected by radionuclide imaging. Clin Nuc Med 30: 630.

7. Rovena B, Medi A, Etmond C, Myzafer K, Rudin D, et al. (2015) Lingual Thyroid Gland: A Case Report. IOSR J Den Med Sci 14: 73-77. 
Citation: Ralli M, Singh G, Parmar P, Gilotra M, Kalyan S, et al. (2016) Lingual Thyroid Causing Dysphagia: A Case Report and Review of Literature. J Cytol Histol 7: 425. doi:10.4172/2157-7099.1000425

Page 3 of 3

8. Amr B, Monib S (2011) Lingual thyroid: A case report. Int J Surg Case Reports 2: 313-315.

9. Batsakis JG, El-Naggar AK, Luna MA (1996) Thyroid gland ectopias. Ann Otol Rhinol Laryngol 105: 996-1000.

10. Gallo A, Leonetti F, Torri E, Manciocco V, Simonelli M, et al. (2001) Ectopic lingual thyroid as unusual cause of severe dysphagia. Dysphagia 16: 220-223.

11. Toso A, Colombani F, Averono G, Aluffi P, Pia F (2009) Lingual thyroid causing dysphagia and dyspnoea. Case reports and review of the literature. AC TA otorhinolaryngologica italic 29: 213-217.

12. Massine RE, Durning SJ, Koroscil TM (2001) Lingual thyroid carcinoma: a case report and review of the literature. Thyroid 11: 1191-1196.
13. Baik SH, Choi JH, Lee HM (2002) Dual ectopic thyroid. Eur Arch Otorhinolaryngol 259: 105-107.

14. Galizia G, Lieto E, Ferrara A, Castellano P, Pelosio L, et al. (2001) Ectopic thyroid: report of a case. G Chir 22: 85-88.

15. Shah BC, Ravichand CS, Juluri S, Agarwal A, Pramesh CS, et al. (2007) Ectopic thyroid cancer. Ann Thorac Cardiovasc Surg 13: 122-124.

16. Jones P (1961) Auto transplantation in lingual ectopia of the thyroid gland: review of the literature and report of a successful case. Arch Dis Child 36: 164-170. 